\title{
Attitude evoked anticipatory responses and attraction
}

WILLIAM GRIFFITT, Kansas State University, Manhattan, Kans. 66502

Predictions based on a reinforcement model of evaluative responses were tested by exposing $S$ s to strangers' attitude scales expressing varying proportions of attitudes which were similar to their own. Attraction toward the stranger, the anticipated positiveness of contact with the stranger, and estimated speed of success in solving a problem with the stranger as a partner were all significantly related to the proportion of similar attitudes expressed by the stranger. All findings were consistent with the reinforcement model of evaluative responses.

In a series of controlled laboratory experiments (Byrne, 1968) it has repeatedly been demonstrated that attraction toward an anonymous stranger is a positive linear function of the proportion of agreeing attitudes expressed by the stranger. The attitude similarity-attraction relationship has been interpreted as a special case of an hypothesized relationship between reinforcement and evaluation as expressed in a formal model proposed by Byrne \& Clore (in press). It is proposed that the evaluation of a given stimulus object $(\mathrm{SO})$ is a positive linear function of the proportion of stimuli with weighted positive reinforcement properties associated with SO. Stimuli with reinforcement properties (RS) are hypothesized to evoke implicit affective responses (AR) which become conditioned to any SO paired with RS and, in turn. mediate verbal evaluative responses to SO (Byrne \& Clore, in press; Griffitt, 1968).

Within the above framework, agreeing and disagreeing attitude statements have been shown to act, respectively, as positive and negative reinforcers in a discrimination learning task (Byrne, Young. \& Griffitt, 1966). In addition, positive or negative affect may be conditioned to anonymous strangers by pairing the latter, respectively, with agreeing or disagreeing attitude statements (Byrne \& Clore, in press).

It is proposed that reinforcing stimuli evoke affective responses which represent, at least in part, reactions which are "anticipatory" (Doob, 1947), "hopeful" (Mowrer, 1960), or "expectative" (Hull, 1952) of future reinforcing situations. The evaluation of a particular SO is considered a direct function of the proportion of positive anticipatory ARs associated with SO. In a previous investigation (Griffitt, 1968) it was shown that attraction responses are more positive to an individual from whom positive reinforcement is anticipated than to one from whom negative reinforcement is anticipated. Although anticipation of positive or negative reinforcement was manipulated by way of instructions in the latter investigation, it was proposed that RS would evoke anticipatory responses which would affect evaluative responses in the same manner as the instructional manipulation. The present experiment was designed to examine the proposition that RS in terms of agreeing and disagreeing attitude statements from an anonymous stranger evoke ARs representative of anticipated positive and negative interactive consequences associated with the stranger. More specifically, it was hypothesized that attraction is a positive function of the proportion of similar attitudes expressed by a stranger and that the anticipated positiveness of a pending interaction with the stranger is a positive function of the proportion of similar attitudes expressed by the stranger.

\section{METHOD}

Students in an introductory psychology course at Kansas State University were administered a 44-item attitude scale. From this initial pool, 27 male and female Ss were selected for the experiment. A few weeks after the initial testing, Ss were requested to participate in the experiment which was described as a two-person problem-solving task. Each $S$ was requested to evaluate an anonymous same-sex stranger on the basis of inspection of his responses to the attitude scale. Each $S$ was told that the attitude scale which he was to inspect had been filled out by another student who, in a second part of the experiment, would serve as his partner in a two-person problem-solving experiment. The attitude-scale responses attributed to the stranger were bogus ones prepared to provide $.25, .50$, or .75 agreement with $\mathrm{S}$. The mythical strangers were evaluated on the Interpersonal Judgment Scale. the last two items of which are summed to yield the measure of attraction with a range of 2 to 14 . In addition, Ss were asked to anticipate the nature of their pending interaction with the stranger in the problem-solving task through ratings on a series of six semantic differential type scales (comfortableuncomfortable, bad-good, high-low, sad-happy, pleasantunpleasant, negative-positive). Ratings on the latter scales were scored from 1 (least positive) to 7 (most positive) and summed to yield a measure of the anticipated positiveness of the pending interaction with a range of 6 to 42 . Further. Ss were asked to predict how many minutes it would take for them and their partners to solve the pending problem by checking one alternative from a scale of minutes ranging from 1 to 30 .

\section{RESULTS}

The means of the attraction responses, interaction anticipation responses, and time estimates are presented in Table 1. Analysis of variance indicated that the agreementdisagreement manipulation produced significant differences with respect to the attraction responses $(F=4.64, \mathrm{df}=2 / 24$, $\mathrm{p}<.05)$, the interaction anticipation responses $(\mathrm{F}=6.75$, $\mathrm{df}=2 / 24, \mathrm{p}<.01)$, and the time estimates $(\mathrm{F}=5.18$, $\mathrm{df}=2 / 24, \mathrm{p}<.05)$.

\section{DISCUSSION}

As hypothesized, the proportion of similar attitudes expressed by a stranger is significantly related to attraction toward the stranger and to the anticipated positiveness of future contact with the stranger. An obvious question, of course, concerns the ordering of the responses referred to above. That is, the present model hypothesizes that anticipatory affective responses mediate verbal evaluative responses to the stranger while the results of the present experiment demonstrate only that differing proportions of similar attitudes evoke differential anticipatory responses and differential attraction responses. Whether the anticipatory responses precede and mediate attraction responses is not clear. When considered in light of the results of a previous investigation (Griffitt, 1968), however, the hypothesis that the anticipatory responses mediate, at least in part, the attraction responses appears to be supported. That is, the previous study demonstrated that direct manipulations of anticipated positiveness of future contact affect attraction responses (anticipated positiveness $\rightarrow$ attraction) while the present investigation has shown that attitude similarity-dissimilarity affects the anticipated positiveness of future contact (similarity-dissimilarity (RS) $\rightarrow$ anticipated positiveness) and

Table 1

Mean Attraction, Anticipated Positiveness, and Time Estimate Responses as a Function of Attitude Similarity

\begin{tabular}{lrrr}
\hline & .25 & .50 & .75 \\
Attraction & 7.22 & 8.11 & 10.56 \\
Anticipated Positiveness & 24.22 & 25.44 & 32.33 \\
Time Estimates (min) & 24.22 & 19.11 & 16.33 \\
\hline
\end{tabular}


experimental deceptions were explained to the Ss and all questions about the procedure were answered.

\section{RESULTS}

As a check on the effectiveness of the attraction manipulation, the preinteraction ratings of partners by $S s$ in the HA and LA conditions were examined in an analysis of variance. There was a very strong effect for Attraction ( $F=97.49 ; \mathrm{df}=1,72 ; \mathrm{p}<.001)$ in the expected direction, and a main effect for $\operatorname{Sex}(F=3.99$; df $=1,72 ; p<.05)$, with females giving more favorable ratings than did males.

The major index of cooperation was frequency of play in the $a_{1} b_{1}$ cells of the two matrices. For analysis, frequencies were summed over 25 trial blocks; the pair was the unit of analysis. Due to heterogeneity of variance, analysis of variance was performed on arcsin transformed scores $\left(X^{\prime}=2\right.$ arcsin $\sqrt{ } \mathrm{X})$. Frequency of cooperative play decreased from Block 1 to Block 2, and thereafter increased (main effect for trials: $F=3.14 ; \mathrm{df}=3,144 ; \mathrm{p}<.05)$. In addition, a main effect for conflict of interest $(\mathrm{F}=3.58 ; \mathrm{df}=1,48 ; \mathrm{p}=.06)$ indicated that the LC generated more cooperation than $\mathrm{HC}$, while females tended to cooperate more than did males $(F=3.24 ; \mathrm{df}=1,48$; $p=.07$ ). Although the HA means were higher than the LA means, the effect was not significant. However, a tabulation of mutually cooperative "lockins" ( 15 trials of $a_{1} b_{1}$ play out of any set of 20 consecutive trials) suggested that such lockins were increasingly likely as attraction increased $\left(\chi^{2}=6.91\right.$; df $=2 ; p<.05)$. For $H A$ conditions there were 12 cooperative lockins, for NA, 7, and for LA, 4 .

Examination of mutual punishment (the $a_{2}, b_{2}$ cell) yielded results similar to those for cooperation; there was more mutual punishment in the HC than in the LC condition $(F=4.18$; $\mathrm{df}=1,48 ; \mathrm{p}<.05$ ); and more for males than for females $(F=5.01 ; d f=1,48 ; p<.05)$. Kruskal-Wallis nonparametric analysis of variance (Hays, 1963) of effects of attraction upon mutual punishment, for LC and HC separately shows a significant difference by attraction in the expected direction for the HC condition ( $p<.05$ ), though not for LC condition. In addition, $a_{2} b_{2}$ lockins are related to attraction: eight of the LA pairs, six of the NA, and none of the HA pairs have such lockins $\left(\chi^{2}=9.68 ; \mathrm{df}=2 ; \mathrm{p}<.05\right)$.

Finally, the effects of interaction upon attraction were examined by including the average pre- and postinteraction ratings on the Semantic-Differential items in an analysis of variance. Interpretation was rendered difficult by a four-way (Attraction by Conflict of Interest by Sex by Time) interaction $(F=4.96 ; \mathrm{df}=1,32 ; \mathrm{p}<.05)$. However, in general it appears that males became less attracted to each other over time, except for those in the LA, HC condition, where they became more attracted; females become more attracted to each other over time.

\section{DISCUSSION}

Results from the present study provide no support at all for the balance position (Swingle, 1966), and suggest that dyadic cooperation in the prisoner's dilemma game and in the bargaining game used by Krauss (1966) is affected in similar ways by attraction and conflict of interest. Whether the discrepancy between the present results and those implied by Swingle's study is due to the absence in the present study of competition-relevant norms which may accompany friendship, or to the presence of a presumably rare event of trust violation by a friend in Swingle's study is not clear. However, the agreement of some of the Oskamp \& Perlman (1967) findings with those of Swingle suggests that differences between mere attraction and friendship contain the explanation.

\section{REFERENCES}

DEUTSCH, M. Cooperation and trust: Some theoretical notes. In M. Jones (Ed.), Nebraska Symposium on Motivation. Lincoln: University of Nebraska Press, 1962. Pp. 275-318.

DEUTSCH, M., \& KRAUSS, R. M. The effects of threat upon interpersonal bargaining. Journal of Abnormal \& Social Psychology, $1960,61,181-189$.

HAYS, W. L. Statistics for psychologists. New York: Holt, Rinehart \& Winston, 1963.

HEIDER, F. The psychology of interpersonal relations. New York: Wiley, 1958.

KRAUSS, R. M. Structural and attitudinal variables in interpersonal bargaining. Journal of Experimental Social Psychology, 1966, 2, 42-55.

OSGOOD, C. E., SUCI, G. J., \& TANNENBAUM, P. H. The measurement of meaning. Urbana, Ill.: University of Illinois Press, 1957.

OSKAMP, S., \& PERLMAN, D. Effects of friendship and disliking on cooperation in a mixed motive game. Journal of Conflict Resolution, $1966,10,221-226$.

RAPOPORT, A., \& CHAMMAH, A. M. Prisoner's dilemma: A study in conflict and cooperation. Ann Arbor: University of Michigan Press, 1965.

SWINGLE, P. G. Effects of emotional relationship between protagonists in a two-person game. Journal of Personality \& Social Psychology, $1966,4,270-279$.

NOTE

1. This research was supported by Grant MH 13229-01 to the second author by the National Institute of Mental Health.

\section{(Continued from page 153)}

attraction in the same manner. In addition, the correlation between attraction responses and anticipated positiveness of interaction responses was equal to $.73(\mathrm{p}<.001, \mathrm{df}=25)$. It seems reasonable, then, to interpret the findings of the previous investigation (Griffitt, 1968) in conjunction with the present findings as being in support of the hypothesis that: Similarity-Dissimilarity (RS) $\rightarrow$ Anticipated Positiveness (AR) $\rightarrow$ Attraction.

An additional finding of the present investigation is that the proportion of similar attitudes expressed by the fictitious problem-solving partner was significantly related to the estimated speed of success in solving the pending problem. The latter finding is in accord with results obtained by Lott \& Lott (1966) demonstrating that learning performance in a group situation is positively related to the degree of attraction among members of the group. experimental social psychology. Vol. 4. New York: Academic Press, 1968.

BYRNE, D., \& CLORE, G. L., JR. A reinforcement model of evaluative responses. Psychological Review, in press.

BYRNE, D., YOUNG, R. K., \& GRIFFITT, W. The reinforcement properties of attitude statements. Journal of Experimental Research in Personality, 1966, 1, 266-276.

DOOB, L. W. The behavior of attitudes. Psychological Review, 1947, 54, 135-156.

GRIFFITT, W. B. Anticipated reinforcement and attraction. Psychonomic Science, 1968, 11, 355 .

HULL, C. L. A behavior system. New Haven: Yale University Press, 1952.

MOWRER, O. H. Learning theory and behavior. New York: Wiley, 1960. LOTT, A. J., \& LOTT, B. E. Group cohesiveness and individual learning. Journal of Educational Psychology, 1966, 57, 61-73.

\section{NOTE}

1. The author would like to thank Earl Seyfert for his assistance in conducting the experiment. 